\title{
New Cultivars Derived from Crosses between Commercial Cultivar and a Wild Population of Papaya Rescued at Its Center of Origin
}

\author{
Mariela Vázquez Calderón, ${ }^{1}$ Manuel Jesús Zavala León, \\ Fernando Amilcar Contreras Martín, ${ }^{3}$ Francisco Espadas y Gil, ${ }^{3}$ \\ Abelardo Navarrete Yabur, ${ }^{2}$ Lorenzo Felipe Sánchez Teyer, ${ }^{1}$ \\ and Jorge M. Santamaría ${ }^{1}$

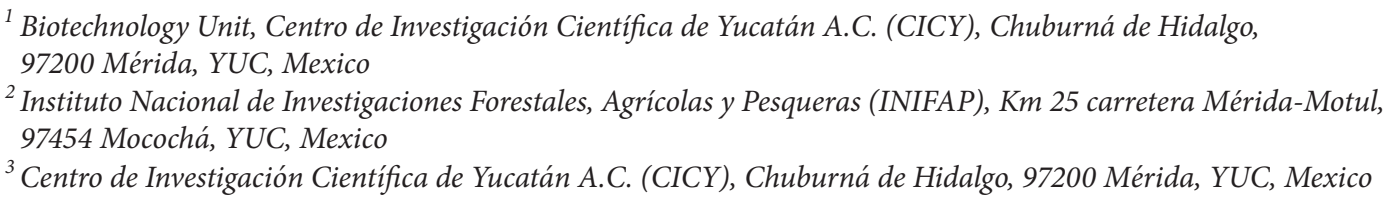

Correspondence should be addressed to Jorge M. Santamaría; jorgesm@cicy.mx

Received 21 May 2014; Revised 16 August 2014; Accepted 18 August 2014; Published 24 September 2014

Academic Editor: Zed Rengel

Copyright (C) 2014 Mariela Vázquez Calderón et al. This is an open access article distributed under the Creative Commons Attribution License, which permits unrestricted use, distribution, and reproduction in any medium, provided the original work is properly cited.

\begin{abstract}
In order to generate new varieties, this study focused on the rescue and use of landraces and wild Carica papaya L. populations located at southern Yucatan, Mexico, to cross them with a commercial papaya cultivar (Maradol). In the cross L7 $\times$ M22, The native parent line L7 was used as the receiver parent while the commercial Maradol (M22) was used as the donor parent, seeking to generate genotypes with improved productivity and reduced plant height. Cluster analysis and principal components analysis grouped the genotypes firstly into those individuals with few fruits and those with many fruits and secondly into individuals with high and low plant height. Selected genotypes H13B, H17B, H19B, H68B, and H71B meet the desirable characteristics, such as reduced plant height (PH) and intermediate number of fruits per plant (NFP). These materials can be used now to produce new crosses to continue with the ongoing breeding program at CICY, seeking new varieties with higher productivity and adequate plant height, and also these genotypes will be preserved and integrated in the germplasm bank in situ and in vitro for further genetic work and possible exchange with other germplasm collections worldwide.
\end{abstract}

\section{Introduction}

The origin of papaya (Carica papaya L.) is Central America and Mexico; wild populations are present from southern Mexico to Belize and the Peten, Guatemala [1]. Currently, it is distributed in all tropical and subtropical areas of the world [2]. It is one of the most cultivated and profitable fruit crops in Mexico and other countries. It also has good digestive properties and medicinal and industrial uses due to its high contents of vitamins B and C and provitamin A as well as the proteolytic enzyme papain $[3,4]$. Moreover, orange redfleshed papaya fruits had important antioxidants in the form of lycopene that was recently shown to be more bioavailable than that from carrots and tomatoes [5]. This crop has had an increasing demand primarily in the markets of USA and Canada. Mexico is the largest exporter worldwide and the fifth papaya producer with a production in 2010 up to 616, 215 ton, a harvested total area of $12,750 \mathrm{ha}$, and a fruit yield of 48.3 ton/ha $[6,7]$.

One of the problems affecting this fruit crop is the reduced number of commercial varieties exploited [8]. In Mexico, other papaya varieties are cultivated such as Hawaiian, Cera, and Mamey but they are grown in low proportions $[9,10]$, while most of the papaya growing areas are devoted to 
the Cuban cultivar, Red Maradol that is susceptible to biotic and abiotic factors. In southern Mexico and particularly in the Yucatan peninsula, there are wild C. papaya populations that have interesting characters to breeders. So it should be possible to take those desirable traits of commercial varieties and mix them with the genetic richness present in wild populations of C. papaya L. in the region to give rise to better adapted materials. With this in mind, other countries have initiated breeding programs with different schemes according to the characters of interest as those they have implemented in Brazil [11], Cuba, Hawaii, Taiwan, South Africa, Australia [12], and Malaysia [13]. Therefore, it is interesting to rescue and use native wild C. papaya populations collected in Mexico (i.e., part of the center of origin of this species $[1,14]$ ) in breeding programs. The genetic variability from the wild populations should be explored and analyzed to identify individuals with outstanding phenotypic characters [15-17], facilitating the identification and selection of potential individuals for inclusion in breeding program of this crop and generating new progenies that combine the phenotypic characteristics through directional selection in relation to the needs of agricultural management and crop productivity, as well as physiological, biochemical, and nutraceuticals properties, in response to market demands.

In the present work, the resulting $\mathrm{F} 1$ and $\mathrm{F} 2$ populations from the crosses between the local parent receiver line 7 and the parent donor M22 $(\mathrm{L} 7 \times \mathrm{M} 22)$ were evaluated using a series of morphological traits in order to identify and select new material to include in the ongoing breeding program seeking new varieties that show both high number of fruits and adequate plant height.

\section{Materials and Methods}

The present work was conducted at the Scientific Research Center of Yucatan (CICY). First, the receiver parent line 7 (L7; hermaphrodite; yellow-fleshed fruits) was crossed with the pollen donor parent Maradol 22 (M22; hermaphrodite; orange-red fleshed fruits).

From one of the fruits resulting from these crosses, 48 seeds were germinated, and the resulting plants were grown until they produced fruits (F1). From those, only 3 individuals were selected and again the flowers were bagged to ensure no contamination with foreign pollen while allowing selfpollination to continue with the F2 characterization (26 genotypes). The seeds from the resulting progeny were propagated in nursery trays under greenhouse conditions for 2 months. They were then transferred to the field where they were managed under commercial fertilization, irrigation, and pestcontrol conditions, until fruit setting 14 months later.

The resulting plantlets showed a sexual type segregation of 28 hermaphrodites and 14 female plants at F1 and 18 hermaphrodites and 8 female plants at F2. Regarding flesh color segregation, the F1 showed 15 yellowed-fleshed fruits and 13 orange-red fleshed fruits, while the F2 showed 1 yellowed-fleshed fruits and 25 red orange-fleshed fruits.

Those hermaphrodite plantlets (28 plants F1 and 15 plants F2) were subjected to further characterization and evaluation of morphoagronomical characters to select superior individuals. The data recorded were plant height $(\mathrm{PH})$, height of first fruit (HFF), stem diameter (SD), petiole length (PL), number of flowers per node (NFLN), number of fruits per node (NFN), and number of fruits per plant (NFP). The selection was made based on international descriptors as reported by [18]. Plant height was measured in $\mathrm{cm}$ from the ground level to the apex of the plant with a measuring tape, stem diameter was measured at $20 \mathrm{~cm}$ above ground level with a graduated vernier in $\mathrm{cm}$, and height of the first fruit was considered from ground level to the appearance of the first fruit. Petiole length was taken from the petiole stem insertion to the center of the leaf. The numbers of flowers per node and fruits per node and per plant were counted. Morphological data were analyzed with the statistical package univariate approach, statistical analysis system (SAS 9.0). Then, multivariate cluster analyses were conducted using the Ward clustering method, based on squared Euclidean distance, and the corresponding dendrogram was constructed with the program InfoStat/L [19]. Principal components analysis of the correlation matrix between characters was performed using NTSYS 2.1.

\section{Results and Discussion}

3.1. Phenotypic Variation. Phenotypic variation and distribution within the $\mathrm{F} 1$ and $\mathrm{F} 2$ populations derived from the cross L7 $\times$ M22 are continuous and normal (Figure 1). As expected, some genotypes were above or below the value of one of or both parents, whereas a proportion of the $\mathrm{F} 1$ and $\mathrm{F} 2$ progenies was grouped between those from both parents, as shown by the mean, maximum, and minimum values for the traits (Table 1).

Figure 2 shows that for the character NFP, 35.7\% of the F1 progeny had less fruits than the parent M22, while $64.3 \%$ of the F1 progeny had intermediate values between those shown by the two parents. For F2, 73.3\% had less fruits than M22, while only $20 \%$ had intermediate values between those of their parents. The remaining $6.6 \%$ could be dismissed for exceeding the NFP of the parent L7.

In relation to plant height (PH), $67.3 \%$ of the $\mathrm{F} 1$ population showed intermediate values between those shown by the parents, while the remaining $32.1 \%$ had higher values than that of the parent L7. However, in F2, only $33.3 \%$ of the population had intermediate $\mathrm{PH}$ values between those of the parents, while $66.6 \%$ showed $\mathrm{PH}$ values above those shown by the parent L7. The mean values of PH and HFF indicated some degree of reciprocity in both $\mathrm{F} 1$ and $\mathrm{F} 2$ progenies. Thus, HFF within the F1 progeny showed a distribution of $17.8 \%$, $42.9 \%$, and $39.3 \%$ which corresponds to values below those of the parent M22, intermediate values between both parents, and values above those of the parent $\mathrm{L} 7$, respectively. The F2 progeny showed $20 \%, 20 \%$, and $60.0 \%$ which corresponds to values below that of the parent M22, intermediate value between both parents, and values above that of the parent L7, respectively.

In conclusion, up to $60.7 \%$ of the F1 progeny and only $40 \%$ of the F2 progeny showed desirable HFF values and favorable harvesting time. The F2 population showed higher 

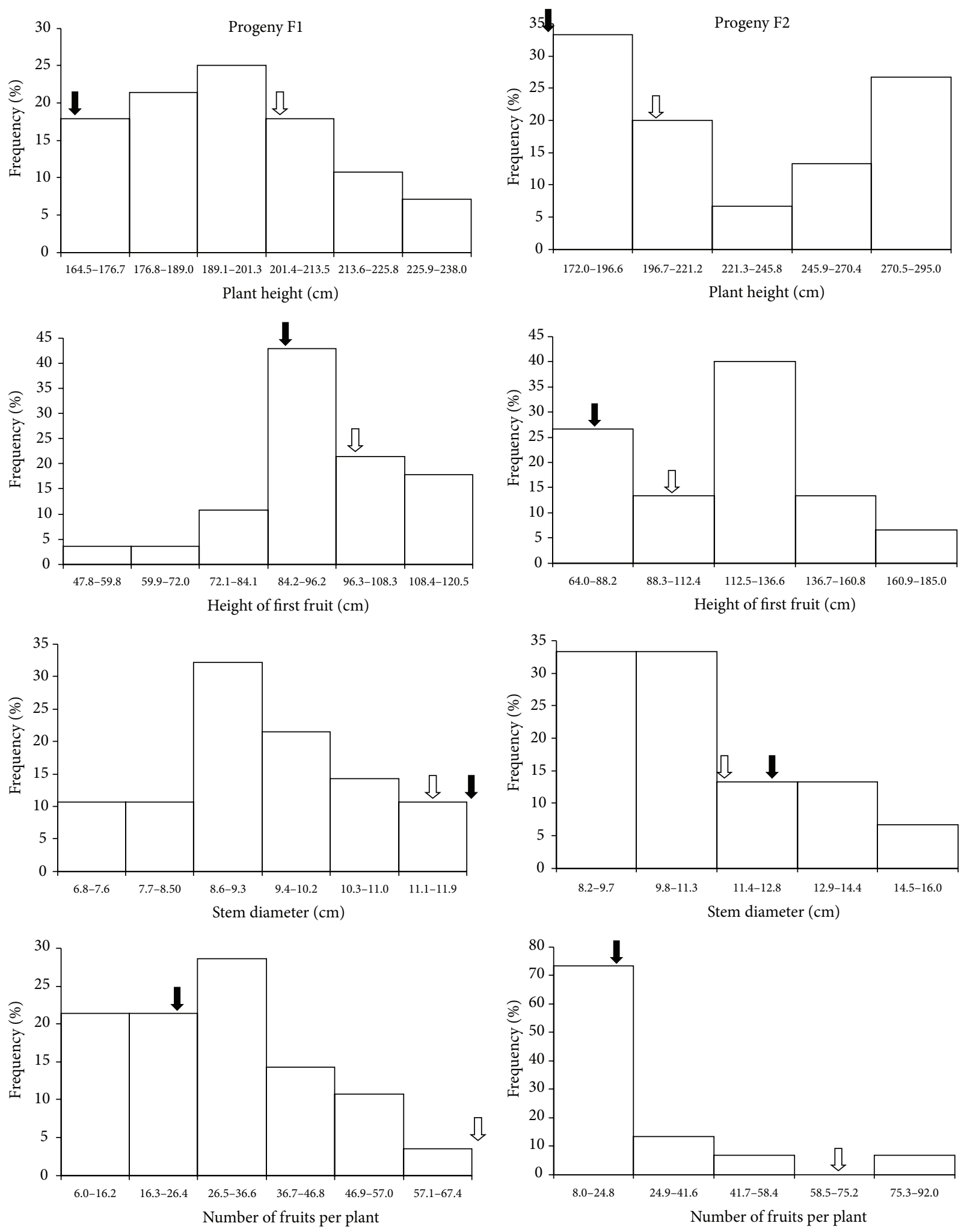

I. Parent line 7 (L7)

IV Parent line 7 (L7)

$\downarrow$ Parent Maradol (M22)

Parent Maradol (M22)

FIGURE 1: Normal distribution of data from PH, HFF, SD, and NFP measured in the F1 and F2 progenies, resulting from the intraspecific cross between L7 × M22. 
TABLE 1: Statistics parameters from values of seven morphological traits measured in the parent lines L7 and M22 as well as in the F1 and F2 progenies, resulting from the intraspecific cross L7 $\times$ M22.

\begin{tabular}{|c|c|c|c|c|c|c|c|}
\hline Parameter & $\mathrm{PH}$ & HFF & $\mathrm{SD}$ & $\mathrm{PL}$ & NFLN & NFN & NFP \\
\hline M22 & 165.2 & 85.0 & 12.2 & 72.0 & 4.0 & 1.8 & 23.8 \\
\hline L7 & 203.0 & 98.0 & 11.5 & 89.0 & 6.0 & 4.0 & 68.0 \\
\hline Mean F1 & 195.5 & 94.8 & 9.36 & 84.1 & 4.2 & 1.3 & 29.5 \\
\hline Mean F2 & 229.6 & 115.0 & 11.1 & 76.4 & 2.6 & 2.2 & 26.6 \\
\hline Minimum F1 & 164.5 & 47.8 & 6.8 & 50.8 & 3.0 & 1.0 & 6.0 \\
\hline Minimum F2 & 170.0 & 62.0 & 6.2 & 50.0 & 1.0 & 1.0 & 6.0 \\
\hline Maximum F1 & 238.0 & 120.5 & 11.9 & 11.8 & 7.7 & 2.3 & 67.5 \\
\hline Maximum F2 & 297.0 & 187.0 & 18.0 & 119.0 & 7.0 & 5.0 & 94.0 \\
\hline S2 F1 & 18.9 & 15.3 & 1.29 & 13.5 & 1.5 & 0.4 & 14.6 \\
\hline S2 F2 & 44.8 & 32.5 & 2.6 & 15.7 & 1.6 & 1.2 & 21.2 \\
\hline CV (\%) F1 & 10.2 & 16.2 & 13.8 & 16.1 & 35.2 & 32.4 & 49.5 \\
\hline $\mathrm{CV}(\%) \mathrm{F} 2$ & 19.5 & 28.3 & 23.5 & 20.5 & 61.5 & 56.8 & 79.9 \\
\hline Normality $^{*} \mathrm{~F} 1$ & 0.9763 & 0.9434 & 0.9676 & 0.9835 & 0.7977 & 0.8243 & 0.9731 \\
\hline Normality $^{*}$ F2 & 0.8893 & 0.9548 & 0.9852 & 0.9487 & 0.8742 & 0.8333 & 0.7148 \\
\hline
\end{tabular}

PH: plant height, HFF: height of first fruit, SD: stem diameter, PL: length of petiole, NFLN: number of flowers per node, NFN: number of fruits per node, NFP: number of fruits per plant, S2: standard deviation, CV: coefficient of variation, L7: parent receiver, M22: parent donor, and F1 and F2: F1 and F2 progenies; ${ }^{*}$ Shapiro-Wilk test.
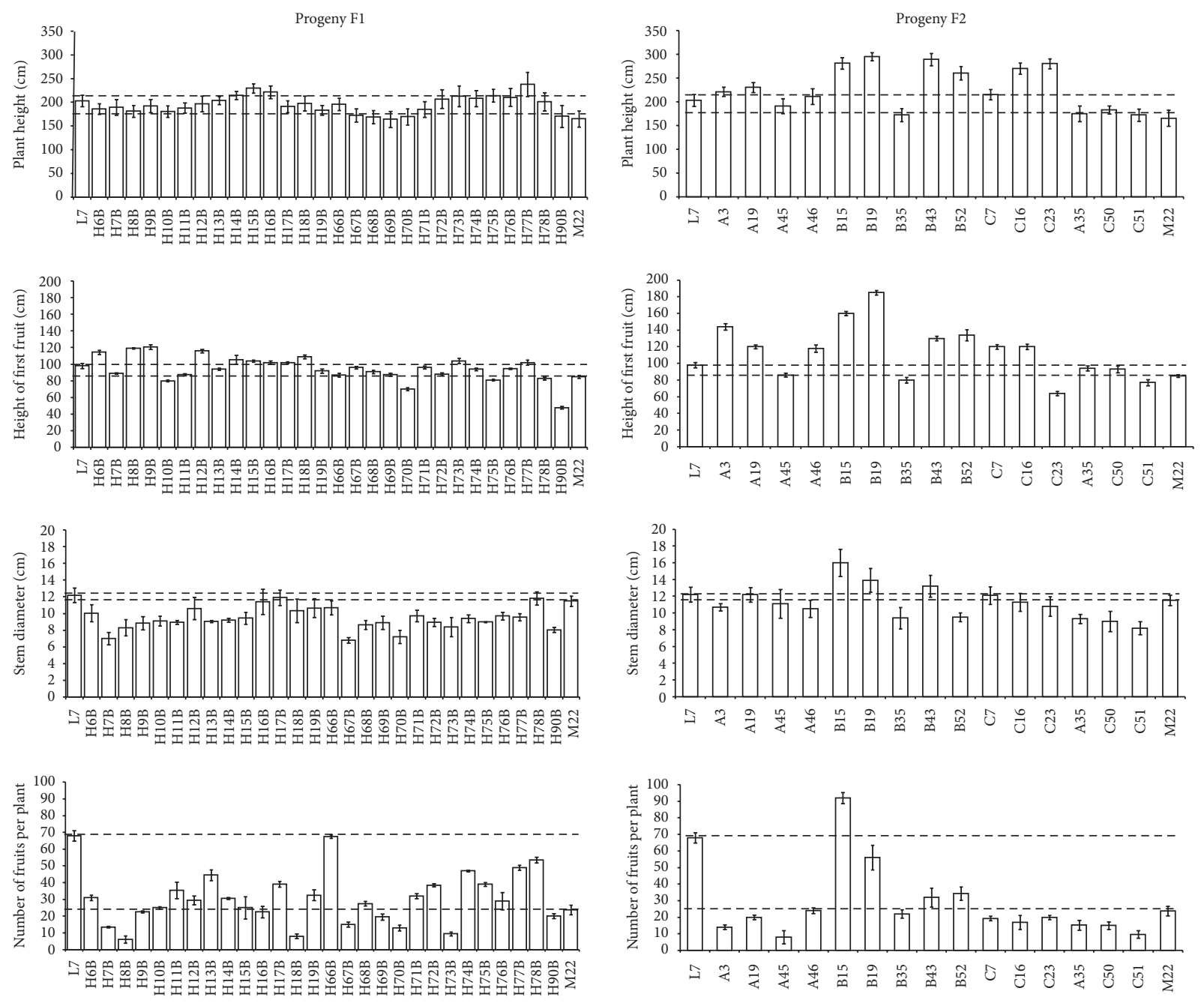

FIgURE 2: Mean values data from PH, HFF, SD, and NFP measured in the F1 and F2 progenies, resulting from the intraspecific cross between L7 $\times$ M22. Data from both parent lines are also shown. Bars represent standard errors. 
proportion of tall plants and plants with few fruits, in such a way that it would be convenient to backcross them with the M22 parent or sibmate them to improve fruit productivity and plant height in the next generation.

3.2. Productivity. L7 and M22 showed contrasting genetic basis in traits of interest such as NFP, PH, and HFF, consistent with the variability observed in the F1 and F2 progenies. Table 1 indicates that data on the number of fruits per plant (NFP), number of flowers per node (NFLN), and number of fruits per node (NFN) represent higher coefficients of variation, ranging from $32.4 \%$ to $49.5 \%$ in the $\mathrm{F} 1$ progeny and from $56.8 \%$ to $79.9 \%$ in the $\mathrm{F} 2$ progeny. Table 2 shows that the NFN and NFLN are strongly associated among them with a correlation of 0.72 to 0.86 in F1 and F2 progenies, respectively. This might suggest that the floral development of more than two flowers and more than one fruit per node, both have a direct effect on the NFP as suggested by de Oliveira et al. [20]. Our data confirm the potential for success in detecting and selecting papaya genotypes with improved productivity.

The mean values of NFN and NFP at both F1 and F2 progenies were closer to those of M22 but lower when compared to the parent L7, indicating that the F1 and F2 populations had promising individuals to be selected on the search of genotypes showing high NFP.

3.3. Plant Height. The $\mathrm{PH}$ and HFF showed a variability of $10.2 \%$ and $16.2 \%$ in $\mathrm{F} 1$ progeny and $29.5 \%$ and $28.3 \%$ in the F2 progeny, respectively. In $\mathrm{PH}$, the $32.14 \%$ of the $\mathrm{F} 1$ population and $66.6 \%$ of the $\mathrm{F} 2$ population exceeded the $\mathrm{PH}$ of the parent L7 that is an undesirable characteristic for the breeder, while $67.86 \%$ and $33.33 \%$ of the $\mathrm{F} 1$ and $\mathrm{F} 2$ progenies, respectively, showed intermediate plant height between those of L7 and M22 parents, which is useful for breeders seeking decreased plant height as indicated by Esquivel et al. [21]. In the case of HFF, $39.29 \%$ of the F1 progeny and $60.0 \%$ of the F2 progeny exceeded the mean value of the parent L7, while $60.71 \%$ in F1 progeny and $20.0 \%$ in $\mathrm{F} 2$ progeny showed intermediate values between those of the parents, a condition that is important and desirable because it may thereby facilitate fruit harvesting up to two cycles and extend the productive life of the plant for longer time, as reported by Muthulakshmi et al. [22] for the progeny of Carica papaya L. CO- $2 \times$ Carica candamarcensis.

3.4. Other Traits. SD had a variability of $13.8 \%$ to $23.5 \%$ in $\mathrm{F} 1$ and F2 progenies. $92.85 \%$ and $66.6 \%$ of the F1 and F2, respectively, showed a slightly lower SD mean value than that of the parents L7 and M22, while 7.15\% of the F1 and $13.3 \%$ of F2 progeny were plants with intermediate SD between those of their parents, while only $20.0 \%$ of the F2 progeny exceeded the stem diameter of the parent M22. In this regard, [23] indicated that SD influences plant vigor, in such a way that the higher the SD, the greater the plant vigor, which is considered as an interesting trait at the time of selecting promising genotypes.

3.5. Cluster Analysis. Data from the parent lines, L7 and M22, as well as those from the F1 and F2 progenies, were subjected to cluster analysis by similarity or dissimilarity, according to the phenotypic trait evaluated. Four groups were obtained by cluster analysis in the F1 population (Table 3(a) and Figure 3(a)). A first group was formed by H6B, H8B, H9B, H12B, H14B, H15B, H16B, H18B, and H73B; a particular feature of this group was the fact that it had the lowest NFP value correlated with a lower NFN and NFLN; thus, they are considered less productive plants [24], and this group also showed the highest HFF mean value.

A second group was formed by $\mathrm{H} 7 \mathrm{~B}, \mathrm{H10B}, \mathrm{H} 11 \mathrm{~B}, \mathrm{H17B}$, H19B, H67B, H68B, H69B, H70B, and H90B. This group, together with the parent M22, exceeded in 20.5\% the first group in terms of NFP, but it showed less $\mathrm{PH}$ and HFF. In a third group formed by H13B, H72B, H74B, H75B, H76B, and $\mathrm{H} 77 \mathrm{~B}$, the $\mathrm{F} 1$ progeny had up to $40 \%$ more NFP than group two, associated with higher $\mathrm{PH}$.

Finally, the fourth group was integrated by the receiver parent L7, together with $\mathrm{H} 66 \mathrm{~B}$ and $\mathrm{H} 78 \mathrm{~B}$, having the highest value of NFP and SD, whereas the PH and HFF mean values indicated that the plants from this group had the lowest plant height.

The grouping of the F2 population is shown in Table 3(b) and Figure 3(b). The first group formed by A35, B35, C50, and C51 as well as the parent M22 had the lowest NFP and the lowest $\mathrm{PH}$ and HFF of the F2 progeny. The second group formed by A3, A19, A46, A45, B43, B52, C7, C16, and C23 had a NFP similar to that of the first group, but it showed $19.6 \%$ and $25.5 \%$ higher $\mathrm{PH}$ and $\mathrm{HFF}$ than the first group, respectively. In a third group, only the parent L7 was considered, showing a NFP value that was more than $70 \%$ higher than the previous group and a relatively low $\mathrm{PH}$ and HFF. Finally, a fourth group was formed by B15 and B19 that had the highest NFP and SD, as well as the highest PH and $\mathrm{HFF}$ within the $\mathrm{F} 2$ population; thus, these are very productive plants but with excessive plant height.

Notably, the SD mean value in the four groups of the F1 and F2 progenies was the highest within each population and showed a correlation with NFP of 0.5309 to 0.5690 in F1 and F2, respectively. Namely, plants that had higher SD had higher NFP. In this regard, [25] noted that a high SD increases the vigor of the plant, as it is directly related to the wider stem xylem vessels that allow increased water, nutrients, and photosynthates to transport to various plant organs that in turn might increase plant productivity [11].

This clustering analysis is useful first to screen genotypes with low or high productivity [24] and second to identify genotypes with less $\mathrm{PH}$ and HFF that is very important and necessary in the process of obtaining genotypes with a lower height, allowing fructification in the lower part of the stem and easy access to the site of insertion of the fruits, which facilitates the process of harvesting.

Carica papaya "cv SOLO" (BH-65) was reported to have a $\mathrm{HFF}$ of $71.1 \mathrm{~cm} \mathrm{[23],} \mathrm{data} \mathrm{that} \mathrm{is} \mathrm{consistent} \mathrm{with} \mathrm{the} \mathrm{criteria}$ established by Marin et al. [26] who pointed out that the criteria to select papaya plants type "SOLO" the HFF should be less than $80 \mathrm{~cm}$. From our F1 progeny results, group two showed HFF values of $80.3 \mathrm{~cm}$ which are similar to the reported data, while the value of HFF in the remaining groups within F1 and F2 (except the fourth group) was below those reported by De Souza et al. [27] for Carica papaya L. "SOLO," 
TABLE 2: Correlation matrixes obtained from the comparison of seven morphological traits measured at F1 (a) and F2 (b) progenies, resulting from the intraspecific cross L7 $\times$ M 22 .

(a) Progeny F1

\begin{tabular}{lcccccc}
\hline & PH & HFF & SD & PL & NFLN & NFN \\
\hline PH & 1.0000 & & & & & \\
HFF & 0.3299 & 1.0000 & & & & \\
SD & 0.3527 & 0.2675 & 1.0000 & & & \\
PL & 0.1097 & 0.1885 & 0.4705 & 1.0000 & & 1.0000 \\
NFLN & 0.2100 & -0.2848 & 0.2989 & 0.3181 & 1.0000 & 0.7178 \\
NFN & 0.1926 & -0.3350 & 0.3651 & -0.0460 & 0.720 & 1.0000 \\
NFP & 0.3473 & -0.1397 & 0.5309 & 0.1761 & 0.7347 & \\
\hline
\end{tabular}

(b) Progeny F2

\begin{tabular}{lcccccc}
\hline & PH & HFF & SD & PL & NFLN & NFN \\
\hline PH & 1.0000 & & & & & \\
HFF & 0.4146 & 1.0000 & & & & \\
SD & 0.3837 & 0.4759 & 1.0000 & & & \\
PL & 0.4795 & 0.4031 & 0.5055 & 1.0000 & & 1.0000 \\
NFLN & 0.3557 & 0.4361 & 0.4603 & 0.4051 & 1.0000 & 0.8622 \\
NFN & 0.2728 & 0.3654 & 0.3295 & 0.3215 & 0.8055 & 1.0000 \\
NFP & 0.4116 & 0.2865 & 0.5690 & 0.3237 & 0.7877 & \\
\hline
\end{tabular}

PH: plant height, HFF: height of first fruit, SD: stem diameter, PL: length of petiole, NFLN: number of flowers per node, NFN: number of fruits per node, NFP: number of fruits per plant, and F1 and F2: F1 and F2 progenies.

TABLE 3: Groups formed by cluster analysis from seven morphological traits in the progeny F1 (a) and progeny F2 (b) resulting from the intraspecific L7 $\times$ M22.

(a) Progeny F1

\begin{tabular}{lccccccc}
\hline Group & PH & HFF & SD & PL & NFLN & NFN & NFP \\
\hline 1 & 201.56 & 110.37 & 9.38 & 69.97 & 3.06 & 1.07 & 1.20 \\
2 & 174.94 & 80.30 & 9.00 & 65.81 & 3.77 & 24.52 \\
3 & 210.59 & 92.27 & 9.24 & 79.88 & 5.42 & 1.43 & 40.88 \\
4 & 198.08 & 89.29 & 11.25 & 76.69 & 6.92 & 2.75 & 62.87 \\
\hline
\end{tabular}

(b) Progeny F2

\begin{tabular}{lccccccc}
\hline Group & PH & HFF & SD & PL & NFLN & NFN & NFP \\
\hline 1 & 193.44 & 85.80 & 9.62 & 64.20 & 2.00 & 1.36 & 2.16 \\
2 & 240.78 & 115.11 & 11.27 & 76.59 & 2.46 & 20.96 \\
3 & 203.00 & 98.00 & 11.50 & 89.00 & 6.00 & 4.00 & 68.00 \\
4 & 288.00 & 172.50 & 14.95 & 103.50 & 5.65 & 4.45 & 79.00 \\
\hline
\end{tabular}

PH: plant height, HFF: height of first fruit, SD: stem diameter, PL: length of petiole, NFLN: number of flowers per node, NFN: number of fruits per node, NFP: number of fruits per plant, and F1 and F2: F1 and F2 progenies.

which was $142-149 \mathrm{~cm}$, and those reported by Muthulakshmi et al. [22] who indicated an HFF of $146.83 \mathrm{~cm}$ in the hybrid of Carica papaya L. generated CO-2 $\times$ Carica candamarcensis. In all cases, the evaluated plants derived from at least one parent with $\mathrm{HFF}$ of about $2.0 \mathrm{~m}$.

3.6. Principal Component Analysis. In order to identify traits that account for most of the observed variance, the data were subjected to principal component analysis. Table 4 shows the main components that describe the largest variation in plant traits evaluated in the F1 and F2 populations. The principal component analysis indicated that PC1, PC2, and PC3 taken together explained $80.99 \%$ and $89.23 \%$ of the total variance in F1 and F2, respectively.

The $\mathrm{PC} 1$ corresponding to $\mathrm{F} 1$ progeny showed a variance of $47.50 \%$ and the traits that explain the greater variability proportion are NFLN, NFN, and NFP, and the same principal component in the $\mathrm{F} 2$ explains $70.14 \%$ of the variance by the characters NFLN, NFN, NFP, and SD.

For PC2, a variance of $21.06 \%$ was obtained to characters $\mathrm{PH}$ and $\mathrm{HFF}$ in the $\mathrm{F} 1$ population, while for $\mathrm{F} 2$ progeny only the character $\mathrm{PH}$ represented a $12.55 \%$ variance. 


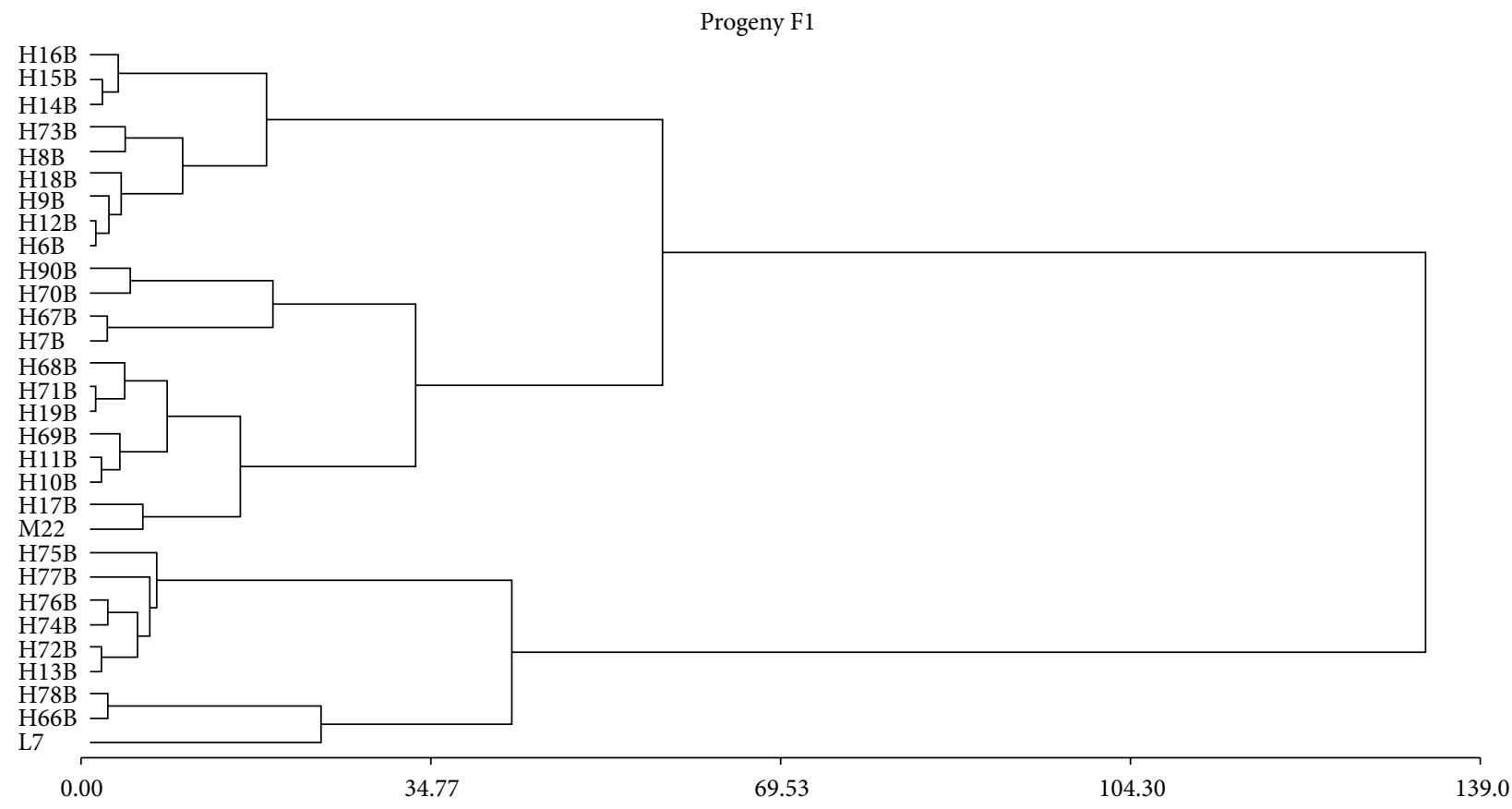

(a)

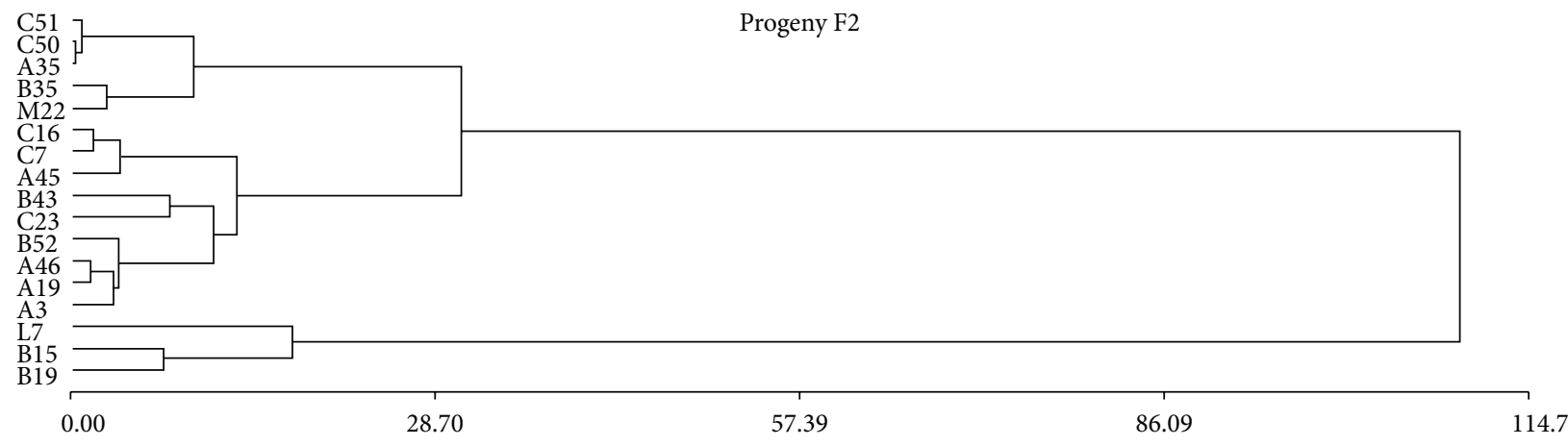

(b)

FIGURE 3: Clustering dendrograms constructed using Ward's method based on the squared Euclidean distances from analysis of seven traits from the F1 (a) and F2 (b) progenies resulting from the intraspecific cross between L7 $\times$ M22. The parent lines L7, parent receiver line 7, and M22, parent donor Maradol 22, are indicated, H6B to H78B and H90B: F1 progeny. A3 to C51: F2 progeny.

PC3 in F1 progeny obtained a 12.42\% variability and in F2 this was $6.54 \%$ represented by the SD and HFF, respectively (Tables $4(\mathrm{a})$ and $4(\mathrm{~b}))$.

The distribution of individuals forming the $\mathrm{F} 1$ and F2 progenies, according to their similarities, is shown in bidimensional graphs; both were grouped according to the variability explained by PC1 and PC2 (Figure 4).

In the F1 population analysis, individuals were grouped in five groups. H66B and $\mathrm{H} 78 \mathrm{~B}$ were grouped in group one, and both individuals had the greatest value for NFP and SD, while values of HP and HFF grouped them as short plants. These short genotypes could be used in papaya breeding programs seeking reduced plant height as reported by Marin et al. [26]. Group two was formed by the individuals L7, H66B, H72B, H70B, H74B, H75B, H76B, and H78B that showed only 10\% and $6 \%$ less NFP and SD, respectively, compared with group one, while values for $\mathrm{PH}$ and $\mathrm{HFF}$ indicate that they are taller plants. H13B, H17B, H19B, H68B, and H71B were grouped in group three that showed similar values to those of the parent line M22 for the characters NFP, SD, PH, and HFF, and these $\mathrm{F} 1$ genotypes represent a rich gene pool that could be considered by breeders in selection of genotypes with desired characteristics (intermediate plant height with intermediate fruit productivity).

The fourth group was formed by the individuals $\mathrm{H} 8 \mathrm{~B}$, H9B, H12B, H14B, H15B, H16B, and H73B that showed low NFP and SD but also showed the highest HFF, parameters that classify them as unsuitable for selection. These undesirable traits are generally associated with longer internodes, widely spaced fruits, and shorter harvesting period $[22,28]$. Group five included the individuals H7B, H10B, H11B, H67B, H69B, $\mathrm{H} 70 \mathrm{~B}$, and $\mathrm{H} 90 \mathrm{~B}$ that showed only $23.4 \%$ more fruit per plant 
TABLE 4: Values and proportion of total variance explained by (a) a principal component analysis and (b) ratio of variability for each trait evaluated in the first three principal components obtained from the morphological analysis of seven traits at the F1 and F2 progenies resulting from the intraspecific cross L7 $\times$ M22.

(a) Principal component

\begin{tabular}{|c|c|c|c|c|c|c|}
\hline & & & \multicolumn{4}{|c|}{ Explained proportion of variance (\%) } \\
\hline & \multicolumn{2}{|c|}{ Eigen value } & \multicolumn{2}{|c|}{ Absolute } & \multicolumn{2}{|c|}{ Accumulated } \\
\hline & $\mathrm{F} 1$ & $\mathrm{~F} 2$ & $\mathrm{~F} 1$ & $\mathrm{~F} 2$ & $\mathrm{~F} 1$ & $\mathrm{~F} 2$ \\
\hline 1 & 3.32 & 4.19 & 47.50 & 70.14 & 47.50 & 70.14 \\
\hline 2 & 1.47 & 0.88 & 21.06 & 12.55 & 68.57 & 82.69 \\
\hline 3 & 0.86 & 0.46 & 12.42 & 6.54 & 80.99 & 89.23 \\
\hline 4 & 0.49 & 0.36 & 7.04 & 5.18 & 88.04 & 94.41 \\
\hline 5 & 0.41 & 0.22 & 5.93 & 3.09 & 93.97 & 97.51 \\
\hline 6 & 0.25 & 0.13 & 3.62 & 1.88 & 97.59 & 99.39 \\
\hline 7 & 0.17 & 0.04 & 12.40 & 0.60 & 100.00 & 100.00 \\
\hline
\end{tabular}

(b) Trait

\begin{tabular}{|c|c|c|c|c|c|c|}
\hline & \multicolumn{6}{|c|}{ Principal component } \\
\hline & \multicolumn{2}{|c|}{$\mathrm{PCl}$} & \multicolumn{2}{|c|}{ PC2 } & \multicolumn{2}{|c|}{ PC3 } \\
\hline & $\mathrm{F} 1$ & $\mathrm{~F} 2$ & $\mathrm{~F} 1$ & $\mathrm{~F} 2$ & $\mathrm{~F} 1$ & $\mathrm{~F} 2$ \\
\hline $\mathrm{PH}$ & 0.5041 & 0.7521 & 0.6965 & 0.5026 & 0.3985 & 0.0229 \\
\hline $\mathrm{HFF}$ & -0.0628 & 0.7656 & 0.8654 & 0.3418 & -0.3354 & 0.4974 \\
\hline SD & 0.6509 & 0.8544 & 0.1763 & 0.1405 & -0.5939 & 0.2003 \\
\hline PL & 0.7503 & 0.8305 & 0.1928 & -0.3630 & -0.0975 & 0.0235 \\
\hline NFLN & 0.7923 & 0.8365 & -0.3214 & 0.2335 & 0.4503 & 0.3873 \\
\hline NFN & 0.8102 & 0.9304 & -0.2280 & -0.4944 & 0.0653 & -0.0318 \\
\hline NFP & 0.8925 & 0.8792 & -0.1309 & -0.2421 & -0.1702 & -0.1351 \\
\hline
\end{tabular}

PH: plant height, HFF: height of first fruit, SD: stem diameter, PL: length of petiole, NFLN: number of flowers per node, NFN: number of fruits per node, NFP: number of fruits per plant, F1 and F2: F1 and F2 progenies, and PC: principal component.

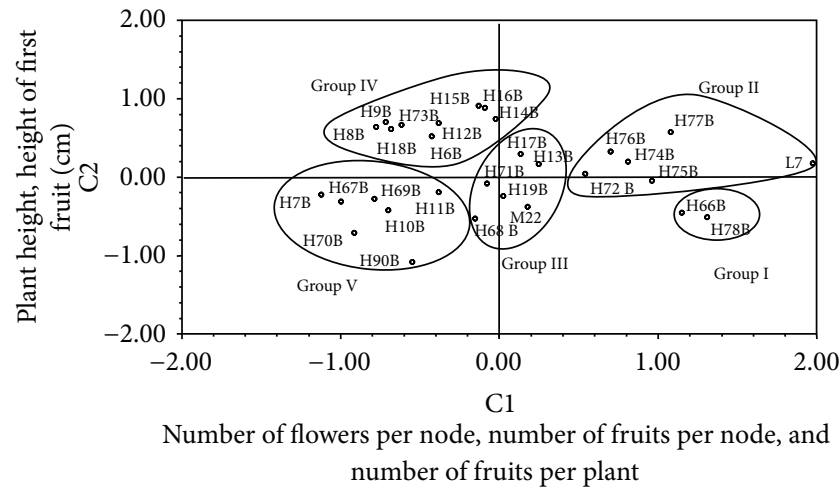

(a)

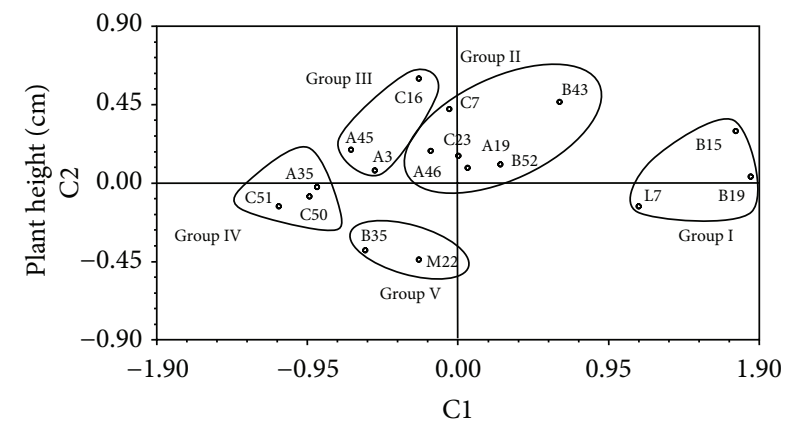

Number of flowers per node, number of fruits per node, and number of fruits per plant

(b)

FIGURE 4: Two-dimensional diagrams of the principal components 1 (PH, HFF) and 2 (NFLN, NFN, and NFP) obtained from the analysis of seven traits in the F1 (a) and F2 (b) progenies, resulting from the intraspecific cross between L7 × M22. Values from both parent lines, L7 and M22, are also indicated.

than group four, while they had values of PH, HFF, PL, and SD that groups them as short plants, although the NFP could be improved by backcrossing.

The F2 population was also grouped into five groups. Group one included B15, B19, and L7, characterized by the largest NFP and PH, HFF, and SD, being the most productive and the tallest plants found in the F2 population. Group two was formed by A19, A46, B43, B52, C7, and C23, which had $65.4 \%$ less NFP and $22.3 \%$ less HFF than group one, although in $\mathrm{PH}$ both groups were very similar. Group three 
included A3, A45, and C16 that showed the lowest NFP of the F2 progeny; however, in $\mathrm{PH}, \mathrm{HFF}$, and SD, they showed a minimum reduction of only $8 \%, 2 \%$, and $3 \%$, respectively, from the values found in group two. Namely, plants from this third group are tall plants with very little fruit number. Group four included A35, C50, and C51, which showed a similar NFP to those from group three, but they had the lowest SD value within the F2 progeny. Likewise, group five composed of B35 and the parent M22 had the lowest PH and HFF within the F2 progeny but exceeded in $48 \%$ the NFP values found in the previous group.

Both clustering methods grouped genotypes based on the NFP trait that showed high variability in F1 and F2 progenies, followed by a dichotomic association with $\mathrm{PH}$ and HFF traits. The correlation of both sets of traits was useful to identify and group those individuals by their different proportion of productivity and plant height. Also in the F1 progeny, 75\% of plants had low fruit productivity while $25 \%$ had high fruit productivity. In the F2 progeny, the proportion of low fruit productive plants increased to $87 \%$, while that of plants with high fruit productivity decreased to $13 \%$. Moreover, F1 progeny had a ratio of $55.0 \%$ of tall plants versus $45.0 \%$ of short plants, while in the F2 progeny, the proportion increased to $73 \%$ of tall plants and only $27 \%$ of short plants. The above-mentioned proportions are consistent with the expected allelic segregation, but both traits were influenced by multiple factors. The proportion of 3:1 for NFP in progenies F1 and F2 infers that they were influenced mainly by a heterozygous condition.

Niklas and Marler [29] reported that wild papayas were taller than cultivated papayas. From our results, the proportion in progenies $\mathrm{F} 1$ and $\mathrm{F} 2$ in that trait showed dominance from local parent L7, because the progenies F1 arose from a parent heterozygous and a recessive homozygous parent, while the proportion found in the F2 progeny was derived from a heterozygous parent. But [30] reported that traits, such as low height, have easy fixing genetics for future generations.

All breeding program seeking new varieties that meets the desirable characteristics requires characterization, evaluation, and selection of elite plants to be used to produce new crosses to continue with the ongoing breeding program. The F1 genotypes selected to obtain the F2 progeny were H10B, H11B, H17B, H19B, H66B, H67B, H68B, H69B, H70B, $\mathrm{H} 77 \mathrm{~B}, \mathrm{H} 78 \mathrm{~B}$, and H90B. Among the F2 plants, the genotypes selected were A3, A19, A35, A46, A45, B35 B43, B52, C7, C23, $\mathrm{C} 50$, and C51 as they met the desirable characteristics such as reduced plant height $(\mathrm{PH})$, a condition that is important and desirable because it may thereby facilitate fruit harvesting. On the other hand, they also show intermediate number of fruits per plant (NFP) between those shown by both parents, which allowed the selection of papaya genotypes with improved productivity. These selected genotypes will provide the genetic base to generate new varieties which can compete with commercial varieties, as they should also show better adaptation to drought, heat, and perhaps diseases.

\section{Conclusion}

Cluster analysis and principal components analysis grouped $\mathrm{F} 1$ and $\mathrm{F} 2$ progenies derived from the cross $\mathrm{L} 7 \times \mathrm{M} 22$ into less and more productive individuals and individuals with low and high plant height, and it can be used reliably as a tool in C. papaya L. for selecting plants that meet the characters of interest to the papaya breeder.

Clustering analysis showed a ratio of $3: 1$ with respect to lower and higher NFP, and in F1 the ratio was $75.0 \%$ and $25.0 \%$, while in $\mathrm{F} 2$ the ratio was $87.0 \%$ and $13.0 \%$. In terms of plant height, it showed a ratio of $1: 1$ in the F1 progeny, with a proportion of $55.0 \%$ and $45.0 \%$; however, a ratio of $3: 1$ was observed in the F2 progeny, corresponding to $27 \%$ and $73 \%$. Namely, the F2 progeny showed the highest proportion of plants with less fruit and tall plants, so it is convenient to backcross it with the parent M22 to improve the number of fruits while maintaining a convenient plant height in the subsequent generations.

The present research will serve as a platform for an ongoing breeding program for genetic improvement of papaya in terms of NFP, $\mathrm{PH}$, and HFF through the selection and integration of native materials with the characteristics of interest. The F1 genotypes selected for obtaining the F2 progeny were $\mathrm{H} 10 \mathrm{~B}, \mathrm{H} 11 \mathrm{~B}, \mathrm{H} 17 \mathrm{~B}, \mathrm{H} 19 \mathrm{~B}, \mathrm{H} 66 \mathrm{~B}, \mathrm{H} 67 \mathrm{~B}, \mathrm{H} 68 \mathrm{~B}$, H69B, H70B, H77B, H78B, and H90B. Among the F2 plants, the genotypes selected were A3, A19, A35, A46, A45, B35 B43, B52, C7, C23, C50, and C51 to continue the ongoing papaya breeding process.

\section{Conflict of Interests}

The authors declare that there is no conflict of interests regarding the publication of this paper.

\section{Acknowledgments}

The authors wish to acknowledge CONACYT for the scholarship 35263 granted to Mariela Vázquez Calderón. The authors wish to thank Professor Raul F. Monforte-Peniche for kindly hosting part of their experiments at his property at Rancho San Pedro Sucilá, Yucatán, México, and Ing. Nelsy Pérez Monforte for providing support in the plantation management.

\section{References}

[1] C. F. Antunes Carvalho and S. S. Renner, "A dated phylogeny of the papaya family (Caricaceae) reveals the crop's closest relatives and the family's biogeographic history," Molecular Phylogenetics and Evolution, vol. 65, no. 1, pp. 46-53, 2012.

[2] M. Mishra, R. Chandra, and S. Saxena, "Papaya," in Genome Mapping and Molecular Breeding in Plants, Fruits and Nuts, C. Kole, Ed., vol. 4, chapter 19, pp. 343-351, Springer, New York, NY, USA, 2007.

[3] E. Amri and F. Mamboya, "Papain, a plant enzyme of biological importance: a review," American Journal of Biochemistry and Biotechnology, vol. 8, no. 2, pp. 99-104, 2012.

[4] R. M. Schweiggert, C. B. Steingass, P. Esquivel, and R. Carle, "Chemical and morphological characterization of Costa Rican papaya (Carica papaya L.) hybrids and lines with particular focus on their genuine carotenoid profiles," Journal of Agricultural and Food Chemistry, vol. 60, no. 10, pp. 2577-2585, 2012.

[5] R. M. Schweiggert, R. E. Kopec, M. G. Villalobos-Gutierrez et al., "Carotenoids are more bioavailable from papaya than from tomato and carrot in humans: a randomised cross-over study," British Journal of Nutrition, vol. 111, no. 3, pp. 490-498, 2014. 
[6] SIAP, 2009, http://www.siap.sagarpa.gob.mx/ventana.php? idLiga $=1150 \&$ tipo $=1$.

[7] FAOSTAT, Estadísticas de producción y consumo mundial de frutas y hortalizas, 2009, http://www.fao.org/statistical\%20 databases.

[8] P. L. Posada, K. R. Gómez, P. J. Pérez, V. M. Reyes, and M. O. Norman, "Development of a new papaya (Carica papaya L.) hybrid IBP 42-99," Interciencia, vol. 35, no. 6, pp. 461-465, 2010.

[9] E. A. Evans and F. H. Ballen, "An overview of global papaya production, trade and consumption," in Topics: Food and Resource Economics, Extension service Institute of Food and Agricultural (IFAS), FE913, pp. 1-7, University of Florida, Gainesville, Fla, USA, 2012.

[10] Infoaserca, 1999, http://www.infoaserca.gob.mx/claridades/revistas/067/ca067.pdf\#page=3.

[11] F. Filho Da Silva, M. G. Pereira, H. C. C. Ramos, P. C. Damasceno Jr., T. N. S. Pereira, and C. D. Ide, "Genotypic correlations of morpho-agronomic traits in papaya and implications for genetic breeding," Crop Breeding and Applied Biotechnology, vol. 7, no. 4, pp. 345-352, 2007.

[12] OECD, "Concensus document on the biology of papaya (Carica papaya)," OECD Enviroment, health and safety publications, series on harmonisation of regulatory oversight in biotechnology no. 33, France, 2005, http://www.oecd.org/science/biotrack/46815818.pdf.

[13] Y. K. Chan, "Stepwise priorities in papaya breeding," Acta Horticulturae, vol. 740, pp. 43-48, 2007.

[14] G. Fuentes and J. M. Santamaría, "Chapter 1: papaya (Carica papaya L.): origin, domestication, and production. Genetics and genomics of papaya," in Plant Genetics and Genomics: Crops and Models, vol. 10, pp. 3-15, Springer, 2014.

[15] T. L. Franco y and R. Hidalgo, Análisis Estadístico de Datos de Caracterización Morfológica de Recursos Fitogenéticos - Boletin Tecnico IPGRI No. 8, Bioversity International, Cali, Colombia, 2003.

[16] L. D. Querol, Recursos Genéticos: Aproximación Técnica y Socioeconómica, Industrial Gráfica, S. A. Lima, Perú, 1998.

[17] J. B. Phipps, Monograph of Northern Mexican Crataegus (Rosaceae), vol. 15 of Botanical Misallany, Botanical Research Institute of Texas INC. BRIT, Fort Worth, Tex, USA, 1997.

[18] International Union for the Protection of New Varieties of Plants (UPOV), Papaya UPOV Code : Caric_pap Carica papaya L., 2010.

[19] J. A. Di Rienzo, F. Casanoves, M. G. Balzanrini, L. Gonzalez, M. Tablada, and C. W. Robledo, InfoStat Versión 2011, Grupo Infostat, FCA, Universidad Nacional de Córdoba, Córdoba, Argentina, 2011, http://www.infostat.com.ar.

[20] E. J. de Oliveira, V. B. O. Amorim, E. L. S. Matos et al., "Polymorphism of microsatellite markers in papaya (Carica papaya L.)," Plant Molecular Biology Reporter, vol. 28, no. 3, pp. 519-530, 2010.

[21] M. Esquivel, Y. Tornet, R. E. Ramos, E. Farrés, A. González, and M. C. Rodríguez, "Caracterización y evaluación de dos híbridos de papaya en Cuba," Agricultura técnica en México, vol. 34, no. 3, pp. 333-339, 2008.

[22] S. Muthulakshmi, T. N. Balamohan, R. Amutha, W. B. Rani, K. Indira, and P. Mareeswari, "Interspecific hybridization in papaya (Carica papaya L.)," Research Journal of Agriculture and Biological Sciences, vol. 3, no. 4, pp. 260-263, 2007.

[23] M. Esquivel, Y. Tornet, R. E. Ramos, E. Farrés, J. Castro, and M. C. Rodríguez, "Evaluación de tres cultivares de papaya del grupo "SOLO" basada en caracteres de crecimiento y productividad," Cultivos Tropicales, vol. 29, no. 2, pp. 59-64, 2008.

[24] E. Mora and A. Bogantes, "Evaluación de híbridos de papaya ( Carica papaya L.) en Pococí , Limón, Costa Rica," Agronomia Mesoamericana, vol. 15, no. 1, pp. 39-49, 2004.

[25] T. T. Martinez, H. J. Vargas, A. O. Muñoz, and U. J. López, "Respuesta al déficit Hídrico en P. leiphylla: consumo de agua y crecimiento en plántulas de diferentes poblaciones," Agrociencia, vol. 36, no. 3, pp. 365-376, 2003.

[26] S. L. D. Marin, M. G. Pereira, A. T. Do Amaral Jr., L. A. P. Martelleto, and C. D. Ide, "Partial diallel to evaluate the combining ability for economically important traits of papaya," Scientia Agricola, vol. 63, no. 6, pp. 540-546, 2006.

[27] R. M. De Souza, J. L. L. Dantas, and J. F. Lima, "Avaliação e caracterização agronómica de germoplasma de mamão," Magistra Cruz das Almas, vol. 13, no. 1, pp. 1-9, 2001.

[28] A. Maruchi, Y. Tornet, R. E. Ramos, E. Farrés, J. Castro, and M. C. Rodríguez, Establecimiento y Evaluación Preliminar de Cultivares de Papaya (Carica papaya L.) Introducidos en Cuba de Interés para el Mejoramiento y la Producción, Instituto de Investigaciones en Fruticultura Tropical (IIFT) Ed, GEF (Grupo Empresarial Frutícola Ciudad de La Habana), Havana, Cuba, 2007.

[29] K. J. Niklas and T. E. Marler, "Carica papaya (Caricaceae): a case study into the effects of domestication on plant vegetative growth and reproduction," The American Journal of Botany, vol. 94, no. 6, pp. 999-1002, 2007.

[30] W. B. Storey, "Genetics of the papaya," Journal of Heredity, vol. 44 , no. 2 , pp. $70-78,1953$. 

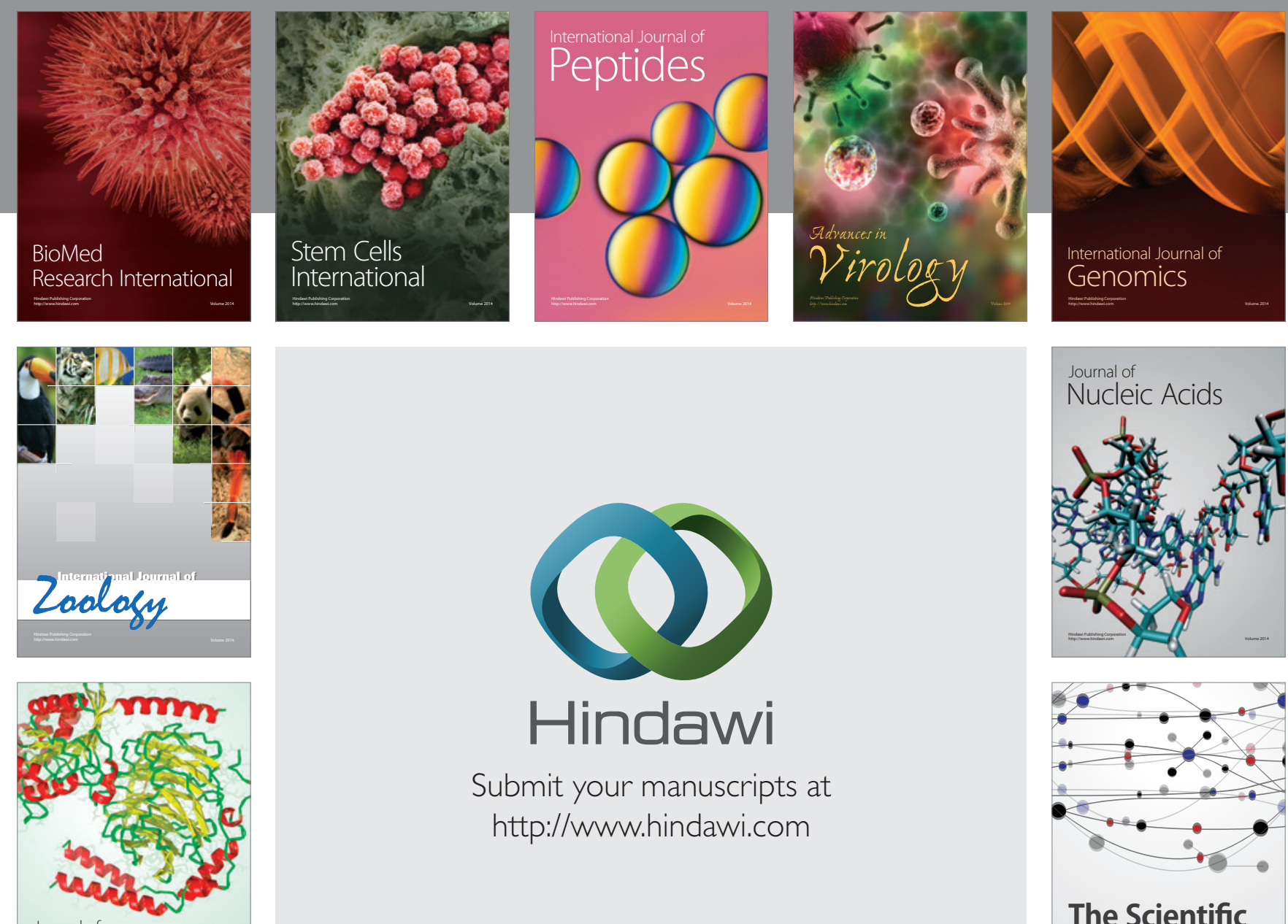

Submit your manuscripts at

http://www.hindawi.com

Journal of
Signal Transduction
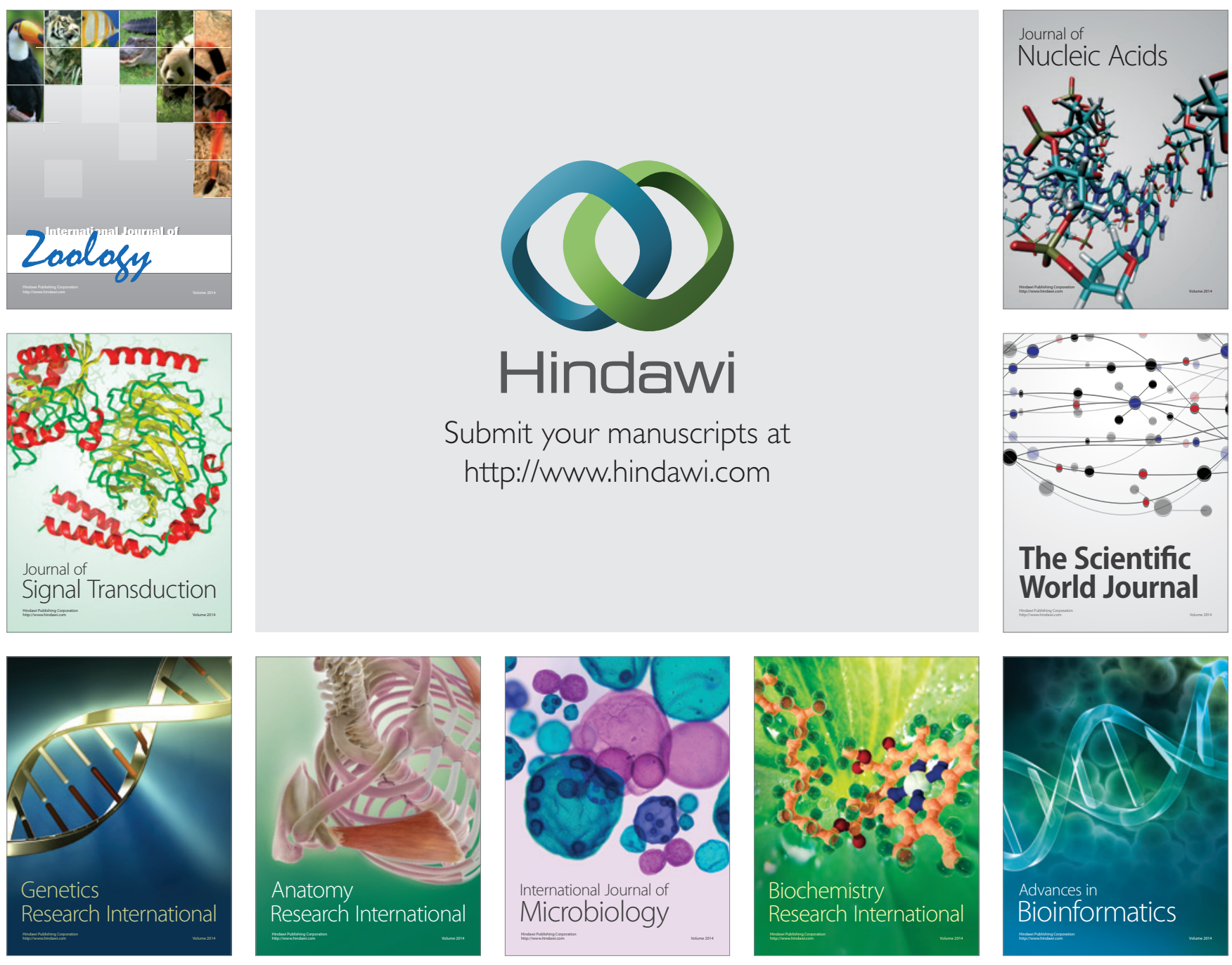

The Scientific World Journal
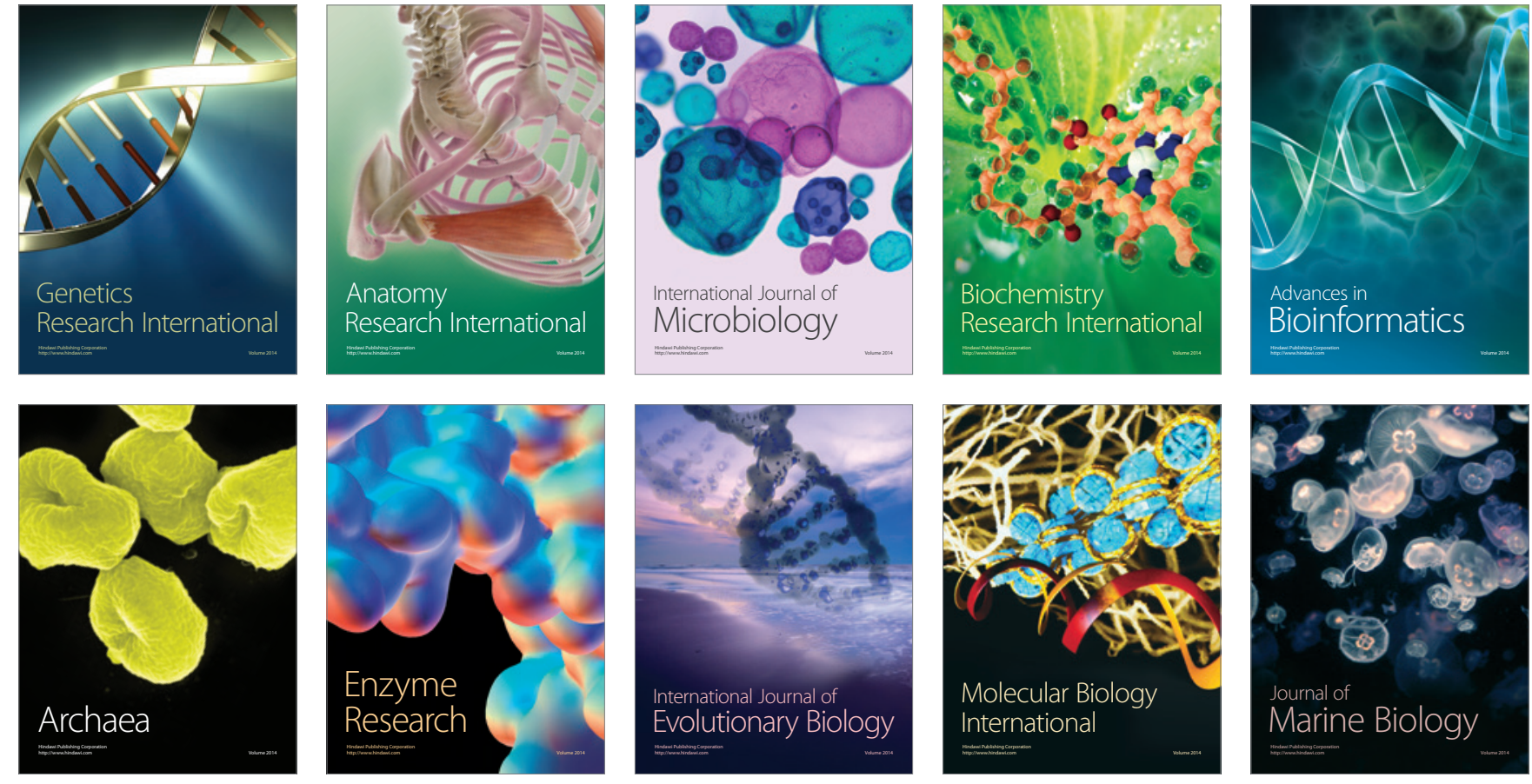